\title{
TREATMENT OF STABLE ANGINA
}

Itsik Ben-Dor, Alexander Battler

Heart 2007;93:868-874. doi: 10.1136/hrt.2005.083659

Take the online multiple choice questions associated with this article (see page 874 )

C oronary artery disease is still highly prevalent worldwide, and stable angina pectoris is one of its more common presentations. Stable angina is a clinical expression of myocardial ischaemia associated with fixed atherosclerotic coronary stenosis, which prevents the adaptation of coronary perfusion to an increased oxygen requirement. The goals of treatment include relief of symptoms, inhibition or slowing of disease progression, prevention of future cardiac events such as myocardial infarction (MI), and improved survival. This article reviews the treatment modalities currently available to alleviate the symptoms of chronic angina and to reduce the risk of future MI and cardiac death, including several novel pharmacological treatments, coronary revascularisation, as well as novel technologies that may benefit selected groups of patients who are refractory to both drugs and revascularisation (fig 1 ).

\section{ANTIANGINAL AND ANTI-ISCHAEMIC DRUGS}

Three major classes of anti-ischaemia drugs are currently used in the medical management of angina pectoris: $\beta$-blockers, nitrates (short- and long-acting), and calcium channel antagonists (table 1). All three have been shown to prolong the duration of exercise before the onset of angina and ST segment depression as well as to decrease the frequency of angina. However, none prevents MI or death caused by coronary disease in patients being treated specifically for chronic stable angina.

Although the clinical guidelines of the American College of Cardiology/American Heart Association (2002) and the European Society of Cardiology (2006) suggest that $\beta$-blockers be used as the first-line agents in patients with stable angina, ${ }^{1-3}$ head-to-head comparative trials failed to demonstrate a greater antianginal efficacy for any one class of drugs over the others. A meta-analysis of 90 randomised or crossover studies yielded no observed differences in rates of cardiac death or MI between $\beta$-blockers and calcium antagonists; too few trials compared nitrates with calcium antagonists or $\beta$-blockers for definitive conclusions to be drawn. Angina episodes were reduced more often with $\beta$-blockers compared to calcium antagonists, particularly nifedipine. ${ }^{4}$ In hypertensive patients, treatment with short-acting (but not long-acting) calcium antagonists (dihydropyridines) led to an increased risk of MI, and at increasingly large doses an increased mortality rate. In the ACTION study involving 7665 patients with angina, the addition of the nifedipine gastrointestinal therapeutic system (GITS, slow release) to conventional treatment had no effect on major cardiovascular event-free survival, although it was associated with a significantly lower need for coronary angiography and interventions. ${ }^{5}$ Another study compared treatment with amlodipine, enalapril or placebo in patients with stable angina and normal blood pressure. Amlodipine significantly reduced hospitalisation for angina compared to placebo, as well as the need for revascularisation during a two year follow-up. Thus, all three classes of antianginal drugs appear to be equally effective for symptom relief, and except for short-acting dihydropyridines, all calcium channel blockers are safe for use. If the patient remains symptomatic, combination treatment with $\beta$-blockers plus nitrates, $\beta$-blockers plus a dihydropyridine calcium antagonist, or a nondihydropyridine calcium channel blocker plus nitrates should be tried.

See end of article for authors' affiliations

\section{Correspondence to:} Professor Alexander Battler, Department of Cardiology, Rabin Medical Center, 39 Jabotinsky Street, Petach Tikva, Israel 49100; abattler@clalit. org.il

\section{New drugs with novel mechanisms of action}

The mode of action of most conventional antianginal agents involves haemodynamic changes, such as a reduction in systemic vascular resistance or coronary vasodilatation or negative inotropism, which improve the imbalance in myocardial oxygen supply and demand. Recently, new drugs based on novel mechanisms of action have emerged ${ }^{6}$ (table 1).

\section{Ranolazine}

Ranolazine (approved recently by the US Food and Drug Administration) is a unique anti-ischaemic drug that does not significantly affect haemodynamic parameters. ${ }^{7}$ It was originally believed to 
Therapeutic opportunities for stable angina

\begin{tabular}{|l|l|}
\hline $\begin{array}{l}\text { Anti-ischaemic therapy-with } \\
\text { haemodynamic effects } \\
\text { - } \text {-blocker }\end{array}$ \\
$\begin{array}{l}\text { - Calcium channel blocker } \\
\text { - Nitrates }\end{array}$ & $\begin{array}{l}\text { New drugs with novel } \\
\text { mechanisms of action } \\
\text { - Ranolazine } \text { - Trimetazidine } \\
\text { - Nicorandil } \text { - Ivabradine } \\
\text { - Fasudil }\end{array}$ \\
\hline PCI/CABG Molsidomine
\end{tabular}

Figure 1 Different modalities of treatment of stable angina. ACE, angiotensin-converting enzyme; $C A B G$, coronary artery bypass grafting; $E E C P$, enhanced external counter pulsation; $P C A B$, percutaneous in situ coronary artery bypass; PCVA, percutaneous in situ coronary venous arterialisation; $\mathrm{PCl}$, percutaneous coronary intervention; TMR, transmyocardial laser revascularisation.

modify the use of substrate by the ischaemic myocardium from lipids to glucose, thereby increasing metabolic efficiency. However, recent studies suggest that it inhibits the late sodium current $\mathrm{I}_{\mathrm{NA}}$ and the accumulation of intracellular sodium and congruent cellular calcium overload via the sodium/calcium exchanger. As opposed to treatment with calcium channel antagonists and $\beta$-blockers, the ranolazine-induced improvement in diastolic function occurs without a decrease in systolic function. Clinical studies of the anti-ischaemic effect of ranolazine monotherapy in patients with stable angina showed a significant increase in exercise duration and an improved $1 \mathrm{~mm}$ ST segment depression compared with atenolol. As an adjunct to standard doses of anti-ischaemia drugs (atenolol, amlodipine, diltiazem), ranolazine had an additional antianginal and anti-ischaemic effect, without causing significant haemodynamic changes. The ERICA study addressed the incremental benefit of adding ranolazine to maximal amlodipine regimen. Ranolazine significantly reduced the frequency of angina and glyceryl trinitrate (nitroglycerin) consumption compared with placebo. It also has another potentially favourable effect-namely, a dose-related reduction in haemoglobin $\mathrm{A}_{1} \mathrm{C}$ concentrations in diabetic patients. More comparative trials of ranolazine with other antianginal agents and studies of its effects on long-term morbidity and mortality are needed. So far, results indicate that ranolazine may serve as a useful alternative or adjunct to conventional antianginal treatment. Adverse effects include constipation, nausea, and dizziness. Postural hypotension due to $\alpha$-adrenergic receptor blocking has also been reported. Increases in QT interval were observed but not associated torsade de points.

\section{Trimetazidine}

Trimetazidine is a pure metabolic agent that induces the myocardium to shift from free fatty acids to predominantly glucose utilisation in order to increase adenosine triphosphate (ATP) generation per unit oxygen consumption. Efficacy studies reported that trimetazidine reduced ischaemia during exercise stress tests, but there was no improvement in outcome. In a Cochrane meta-analysis of 23 studies including 1378 patients, trimetazidine was associated with a significant reduction in weekly angina episodes and improved exercise time to $1 \mathrm{~mm}$ ST segment depression compared to placebo. ${ }^{8}$ In patients with stable angina who experienced concomitant erectile dysfunction, trimetazidine plus sildenafil was both safe and more effective in controlling episodes of ischaemia during sexual activity than nitrates alone. These data indicate that trimetazidine is safe and effective for the treatment of symptoms of stable angina, either as monotherapy or adjunctive treatment.

\section{Nicorandil}

Nicorandil exerts dual actions: it increases the opening of ATPgated $\mathrm{K}^{+}$channels, thereby relaxing smooth muscle and contributing to coronary vasodilatation; and it has a nitratedonating moiety. Nicorandil may mimic the natural process of ischaemic preconditioning, which involves ATP-dependent potassium channels. Several small randomised trials of patients with stable angina have shown that nicorandil prolongs the time to onset of ST depression and exercise duration during stress testing and improves myocardial perfusion at rest and with exercise. In the IONA trial of 5126 patients, the administration of nicorandil in addition to standard treatments reduced the primary end point (coronary death, MI, or hospitalisation for angina) by 17\% after a mean follow-up of 1.6 years. There was also a significant reduction in the incidence of acute coronary syndrome and all cardiovascular events. ${ }^{9}$

\section{Ivabradine}

Ivabradine inhibits the $\mathrm{I}_{\mathrm{f}}$ channel in the sinus node, thereby causing bradycardia but without any negative inotropic effects. Double-blind trials showed that ivabradine treatment increased exercise time to $1 \mathrm{~mm}$ ST segment depression and limited angina compared to placebo, and had similar clinical effects to atenolol or amlodipine-namely, a two-third reduction in the number of anginal episodes and an increase in total exercise duration. Ivabradine offers clear therapeutic benefit for a whole range of patients with stable angina, including those with contraindication or intolerance to $\beta$-blockers; however, its effect on survival remains to be explored. ${ }^{10}$

\section{Fasudil}

Fasudil is an inhibitor of rho kinase, an intracellular signalling molecule involved in the vascular smooth muscle contractile response. In patients with stable angina, fasudil treatment led to a significantly greater time to $>1 \mathrm{~mm}$ ST segment depression, but showed no difference from placebo in decreasing the time to angina, frequency of angina, or glyceryl trinitrate use.

\section{Molsidomine}

Molsidomine is a nitric oxide donating vasodilator. When compared with placebo, it reduced the incidence of anginal attacks and use of sublingual nitrates, and increased exercise capacity, in patients with stable angina. Higher doses provided better protection from angina, although hypotension was a side effect.

These new drugs are not yet in routine clinical use; however, they may serve as useful alternatives or adjuncts to conventional antianginal treatment. Further studies and longer followup will determine their place in preventing death or MI. 
Table 1 Treatments for stable angina

\begin{tabular}{|c|c|c|c|c|c|c|c|c|}
\hline & Mechanisms & $\begin{array}{l}\text { Improvement } \\
\text { in total } \\
\text { exercise time }\end{array}$ & $\begin{array}{l}\text { Improvement } \\
\text { in time to onset } \\
\text { of ST segment } \\
\text { depression }\end{array}$ & $\begin{array}{l}\text { Decrease in } \\
\text { frequency of } \\
\text { anginal episodes }\end{array}$ & $\begin{array}{l}\text { Reduced } \\
\text { revascularisation }\end{array}$ & $\begin{array}{l}\text { Prevention } \\
\text { of } \mathrm{MI}\end{array}$ & $\begin{array}{l}\text { Improvement } \\
\text { in survival }\end{array}$ & Other effects \\
\hline \multicolumn{9}{|c|}{ Drugs with haemodynamic effects } \\
\hline$\beta$-blockers & Reduces oxygen consumption & + & + & + & - & - & - & \\
\hline $\begin{array}{l}\text { Calcium } \\
\text { channel } \\
\text { antagonists }\end{array}$ & $\begin{array}{l}\text { Increases coronary blood } \\
\text { flow, reduce oxygen } \\
\text { consumption* }\end{array}$ & + & + & + & + & - & - & $\begin{array}{l}\text { Prevent } \\
\text { atherosclerosis } \\
\text { progression }\end{array}$ \\
\hline Nitrates & Increases coronary blood flow & + & + & + & - & - & - & $\begin{array}{l}\text { Antiplatelet } \\
\text { activity }\end{array}$ \\
\hline $\begin{array}{l}\text { Omapatrilat } \\
\text { Drugs with me }\end{array}$ & $\begin{array}{l}\text { Inhibits ACE and neutral } \\
\text { endopeptidase } \\
\text { etabolic effects }\end{array}$ & + & + & NA & - & - & - & \\
\hline Ranolazine & $\begin{array}{l}\text { Inhibitors INA channel leads } \\
\text { to metabolic switch }\end{array}$ & + & + & + & NA & NA & NA & \\
\hline Trimetazidine & & + & + & + & NA & NA & NA & \\
\hline Ivabradine & Slows heart rate, If inhibits & + & + & + & NA & NA & NA & \\
\hline Nicorandil & $\begin{array}{l}\text { Opens potassium channels } \\
\text { and nitrate properties }\end{array}$ & + & + & + & NA & + & + & $\begin{array}{l}\text { Improvement } \\
\text { in myocardial } \\
\text { perfusion }\end{array}$ \\
\hline $\begin{array}{l}\text { Fasudil } \\
\text { Non-pharmac }\end{array}$ & $\begin{array}{l}\text { Inhibits rho kinase } \\
\text { ological strategies }\end{array}$ & - & + & - & NA & NA & NA & \\
\hline EECP & $\begin{array}{l}\text { Increases coronary blood } \\
\text { flow, reduce afterload }\end{array}$ & + & + & + & - & - & - & $\begin{array}{l}\text { Improvement } \\
\text { in myocardial } \\
\text { perfusion† }\end{array}$ \\
\hline TMR & & - & + & + & - & - & - & \\
\hline SCS & & + & + & + & - & - & - & \\
\hline Gene therapy & & + & + & + & - & - & - & \\
\hline
\end{tabular}

$\mathrm{ACE}$, angiotensin-converting enzyme; EECP, enhanced external counter pulsation; MI, myocardial infarction; SCS, spinal cord stimulation; TMR, transmyocardial laser revascularisation.

*Non-dihydropyridine.

†Not in a recent blinded analysis.

\section{DRUGS TO PREVENT MYOCARDIAL INFARCTION AND DEATH}

There is considerable evidence that lifestyle changes and pharmacologic treatment may reduce the progression of atherosclerosis and stabilise plaque in patients with chronic stable angina. Therefore, risk factor modification should be the central component of management. ${ }^{11}$ Suggested lifestyle changes include cessation of smoking, exercise and weight reduction, in addition to treatment of hypertension and glycaemic control in patients with diabetes. There are also numerous drugs available to improve prognosis by preventing MI and death.

Aspirin at a dose of 75-325 mg per day reduces cardiovascular morbidity and mortality by $33 \%$ in patients with coronary artery disease. Most of the data, however, are derived from patients with acute coronary syndrome. Only one study reported a beneficial effect of aspirin in patients with chronic angina pectoris. Clopidogrel, a thienopyridine derivative, has been found to be more effective than aspirin in reducing cardiovascular events in patients with atherosclerotic vascular

\section{Mechanisms of new treatments for stable angina}

- Metabolic and/or ion modulators (ie, ranolazine, trimetazidine)

- Opening ATP-gated $\mathrm{K}^{+}$channels-preconditioning (ie, nicorandil)

- Sinus node inhibition (ie, ivabradine)

- Rho-kinase inhibition (ie, fasudil)

- Endopeptidase inhibition (ie, omapatrilat) disease. However, a more recent study reported that clopidogrel combined with aspirin was not significantly more effective than aspirin alone in reducing the rate of MI, stroke, or death from cardiovascular causes in patients with stable cardiovascular disease or multiple cardiovascular risk factors. ${ }^{12}$ Dipyridamole is often recommended as an adjunctive antiplatelet agent to aspirin in patients after a cerebrovascular event, but it can enhance exercise-induced myocardial ischaemia in patients with stable angina.

There is a plethora of evidence (which is beyond the scope of this review) to show that statins lower the rate of coronary events and mortality by $25-35 \%$ in patients with coronary artery disease. ${ }^{13}$ Current guidelines recommend a target fasting low density lipoprotein cholesterol value of $<100 \mathrm{mg} / \mathrm{dl}$ $(<2.59 \mathrm{mmol} / \mathrm{l})$ in patients with stable angina. The most recent National Cholesterol Education Program directive (NCEP-ATP III) suggests a target of $<70 \mathrm{mg} / \mathrm{dl}(<1.81 \mathrm{mmol} / \mathrm{l})$ for highrisk patients (those with diabetes, multivessel disease, multiple risk factors).

Two large clinical trials (EUROPA, HOPE) found angiotensin-converting enzyme (ACE) inhibitors effective in reducing morbidity and mortality in high-risk patients with cardiovascular disease. However, the PEACE trial failed to find a statistically significant reduction in clinical cardiovascular events. This discrepancy may be due to inclusion of a low-risk patient population in the PEACE trial. More recently, studies reported a consistent benefit of ACE inhibitors in high-, intermediate- and low-risk patients. ${ }^{14}$ Omapatrilat, an ACE inhibitor and neutral endopeptidase, prolonged total exercise duration, time to onset of angina, and time to onset of ischaemic ST segment changes compared with placebo. 
Those vasculoprotective drugs are essential in the treatment of patients with stable angina-every patient should receive an antiplatelet agent and a statin, and probably an ACE inhibitor as well. The European Society of Cardiology guidelines ${ }^{3}$ recommend ACE inhibitors for patients with a co-existing history of MI, hypertension, left ventricular dysfunction, diabetes, or impaired renal function.

\section{Surgical revascularisaton}

\section{Pharmacotherapy vs revascularisation}

Two meta-analyses of randomised trials comparing the efficacy of percutaneous coronary intervention (PCI) and medical treatment in patients with stable angina found similar MI and mortality rates in the two groups, though the patients undergoing PCI were less likely to have angina and more likely to require coronary artery bypass grafting $(\mathrm{CABG}) .{ }^{15}{ }^{16}$ The rates of subsequent revascularisation were similar as well. The authors concluded that PCI should be reserved for patients in whom symptoms are poorly controlled by medical treatment. The results of the ACIP trial indicate that patients who are asymptomatic or have minimal symptoms but demonstrable ischaemia may have a better outcome (lower mortality and MI) with revascularisation with either CABG or PCI compared with those managed medically. However, there are a number of important limitations in applying these results to current clinical practice. First, the patients tested represented only a small percentage of the total number screened and were not reflective of the general population. Second, most of the studies

\section{Abbreviations}

- ACE: angiotensin-converting enzyme

- ACIP: Asymptomatic Cardiac Ischemia Pilot

- ACTION: A Coronary disease Trial Investigating Outcome with Nifedipine gastrointestinal therapeutic system

- ARTS: Arterial Revascularization Therapies Study

- ATP: adenosine triphosphate

- CABG: coronary artery bypass grafting

- EECP: enhanced external counter pulsation

- ERACI III: Argentine Randomized Trial of Percutaneous Transluminal Coronary Angioplasty versus Coronary Artery Bypass Surgery in Multivessel Disease

- ERICA: Efficacy of Ranolazine in Chronic Angina

- EUROPA: European Trial with Perindopril in Stable Coronary Artery Disease

- FGF: fibroblast growth factor

- HOPE: Heart Outcomes Prevention Evaluation study

- IONA: Impact Of Nicorandil in Angina

- Ml: myocardial infarction

- MUST-EECP: Multicenter Study of Enhanced External Counter Pulsation

- PCl: percutaneous coronary intervention

- PEACE: Prevention of Events with Angiotensin Converting Enzyme Inhibition

- PICAB: percutaneous in situ coronary artery bypass

- PICVA: percutaneous in situ coronary venous arterialisation

- PMR: percutaneous laser revascularisation

- SCS: spinal cord stimulation

- SoS: Stent or Surgery

- TMR: transmyocardial laser revascularisation

- VEGF: vascular endothelial growth factor were conducted when the use of saphenous vein grafts rather than internal mammary artery grafts was prevalent. Third, the patients who underwent PCI did not receive the current antithrombotic regimens or drug-eluting stents that notably reduced the rate of restenosis and, therefore, revascularisation.

Revascularisation with CABG was found to improve survival compared to medical management in selected patients with stable angina: patients with left main or three-vessel coronary disease; patients with two-vessel disease and significant lesions in the proximal left anterior descending artery; and patients with multivessel disease in the presence of left ventricular dysfunction or diabetes.

\section{$\mathrm{PCl}$ vs $\mathrm{CABG}$}

A number of large randomised trials in the 1990s directly compared CABG with PCI. Their major finding was that survival was similar for the two modes of management, although PCI was associated with more repeated interventions. One important exception was patients with insulin-requiring diabetes, who had a significantly higher five year survival rate after CABG than after PCI (BARI trial). An observational analysis using a database of more 59000 patients also showed a survival advantage for CABG in patients with left main triplevessel disease with proximal left anterior descending artery involvement.

It should be noted that similar to comparisons of PCI and pharmacotherapy, the early trials did not use stents or internal mammary artery grafts. These limitations were overcome in the ARTS I and SoS randomised trials comparing CABG with mostly arterial grafts to PCI with stent implantation. Outcomes were similar in the two groups, except for a much higher rate of target vessel revascularisation with PCI. The ARTS II registry indicated that the solution may lie in the use of drug-eluting stents. The rate of major adverse cardiac and cerebrovascular events in this study was similar to that of the CABG arm in the ARTS I trial and significantly lower than that of the PCI with bare metal stent arm. After adjusting for risk factors, the authors noted a lower rate of major cardiovascular and cerebrovascular events in the PCI arm of ARTS II than in the CABG arm of ARTS I. However, treatment assignment was not random.

Most of the patients included in these randomised trials were relatively low risk-fewer than $20 \%$ had left ventricular dysfunction and almost $70 \%$ had one- or two-vessel diseaseand therefore were compatible with the patient group from whom CABG had not been found to be superior to PCI therapy.

CABG has an advantage over PCI, which does not detect unstable plaques or the lesions most likely to be the cause of subsequent cardiac events. The National Heart, Lung, and Blood Institute Dynamic Registry reported that approximately $6 \%$ of patients after PCI have clinical plaque progression requiring non-target lesion repeat PCI by one year. A greater coronary artery disease burden confers a significantly higher risk of clinical plaque progression. Furthermore, PCI carries a risk of subacute and late stent thrombosis and a need for prolonged anti-aggregation treatment. A recent trial comparing PCI with CABG in patients with multivessel disease (ERACI III) reported a higher rate than expected of stent thrombosis $(3.1 \%$ in 18 months). These data indicate that both revascularisation techniques are appropriate and comparable in outcome, except 
in patients with left main, three-vessel disease and in diabetics in whom CABG is currently preferred.

\section{OTHER TREATMENTS FOR PATIENTS WITH REFRACTORY ANGINA}

Despite the increasing success of conventional medical treatment and the continued development and improvement of mechanical revascularisation approaches, a significant number of patients $(5-10 \%)$ continue to have severe angina. For the many who are not candidates for revascularisation, there are currently several options. ${ }^{17-19}$

\section{Enhanced external balloon counterpulsation (EECP)}

EECP increases arterial blood pressure and retrograde aortic blood flow during diastole. Cuffs are wrapped around the patient's legs, and the compressed air applies sequential pressure (300 $\mathrm{mm} \mathrm{Hg}$ ) from the lower legs to lower and upper thighs in early diastole. The mechanisms underlying the benefits of this procedure in patients with angina are not clear, but may involve non-specific placebo effects and various haemodynamic factors that improve endothelial function and the release of growth factors which promote the formation of collaterals in the coronary circulation. This technique is contraindicated in patients with aortic regurgitation or peripheral vascular disease. In the MUST-EECP trial, patients undergoing active EECP showed a significant increase in time to $>1 \mathrm{~mm}$ ST segment depression and a decrease in anginal episodes compared to the inactive group. Similar findings were noted in an analysis of multicentre registries. One recent study in patients with stable angina did not find a significant effect of EECP on myocardial perfusion. Although EECP is a valuable outpatient procedure, most of the studies conducted so far were small and uncontrolled. Therefore, EECP therapy should be limited at present to patients with debilitating angina who are not candidates for revascularisation and who remain symptomatic even with maximal antianginal pharmacotherapy.

\section{Spinal cord stimulation}

Spinal cord stimulation (SCS) is performed by placing a lead in the epidural space at the level of C7 through Tl and surgically implanting a pacemaker-sized generator in the left lower abdominal area. Patients receive $1 \mathrm{~h}$ of stimulation a day and can activate the device with a handled magnet to treat breakthrough pain. The beneficial effects of the technique on angina are explained by its suppression of the capacity of intrinsic cardiac neurons to generate activity during myocardial ischaemia, or its resolution of sympathetic activity, leading to improved myocardial blood flow. In patients with refractory angina, SCS increases the time to onset of ST segment depression and increases exercise capacity, thereby reducing the number of anginal attacks and the use of glyceryl trinitrate. The main reported adverse reactions were epidural haematoma and infection, occurring in about $1 \%$ of patients. In addition, SCS may interfere with the function of pacemakers and implantable defibrillators. So far, clinical trials have included only small samples, and none had a sham-controlled arm to prevent a placebo effect.

\section{Laser revascularisation}

This technique involves the use of laser ablation to create transmural channels in the ischaemic myocardium in order to restore myocardial perfusion. It can be performed surgically, known as transmyocardial laser revascularisation (TMR), or percutaneously, known as percutaneous laser revascularisation (PMR). The mechanism whereby it alleviates anginal symptoms is unknown. Though the clinical improvement was originally attributed to better myocardial perfusion through open channels, more recent studies have shown that the channels fill with necrotic debris and close shortly after the procedure. Other proposed mechanisms include angiogenesis through the release of growth factors and denervation of pain fibres by laser.

Investigations of the use of TMR for refractory angina revealed an improvement in symptoms and exertion tolerance, but not in myocardial perfusion or mortality rate. In a study of 298 patients with refractory angina randomised to receive PMR or a sham procedure, no between-group differences were noted in exercise duration, exercise time to onset of chest pain, exercise time to the appearance of ST segment changes, or myocardial perfusion. Moreover, the laser treatment was associated with an increased rate of adverse clinical events at 30 days. ${ }^{20}$ Two smaller randomised trials found similar results. The only sham-controlled trial to show benefit was conducted by Salem and colleagues, wherein more patients in the PMR group had a decrease of two or more anginal classes. Therefore, we conclude that PMR is not effective for the treatment of chronic angina. The benefit reported for TMR may be due to a placebo effect.

The SpiRiT trial randomised patients with refractory angina to SCS or PMR. There were no differences in angina-free exercise capacity, angina class, and quality of life between treatments. The patients receiving SCS had more adverse events in the first 12 months, mainly angina or SCS-system related.

\section{Percutaneous in situ coronary venous arterialisation}

Percutaneous in situ coronary venous arterialisation (PICVA) redirects arterial blood flow from the occluded artery into an adjacent coronary vein, thereby arterialising the vein and providing retroperfusion to the ischaemic myocardium. Percutaneous in situ coronary artery bypass (PICAB) redirects the arterial blood flow from a diseased artery to an adjacent coronary vein, and then back to the artery after the lesion is bypassed. PICVA and PICAB hold enormous therapeutic potential for patients whose anatomic findings are incompatible with traditional revascularisation procedures. However, they must still be considered experimental owing to their high procedural complication rate.

\section{Therapeutic myocardial angiogenesis with growth factors, gene and cell therapy}

The dearth of effective treatment strategies for "no option" patients, together with progress achieved in understanding the complex mechanisms inherent in the development of new blood vessels, has facilitated a new treatment strategy commonly termed therapeutic myocardial angiogenesis. Postembryonic angiogenic mechanisms involve growth factors- the most important are vascular endothelial growth factor (VEGF) and basic fibroblast growth factor (FGF). Because of this, supporters of therapeutic angiogenesis advocate the administration of angiogenic growth factor protein or gene packaged in either a plasmid or an adenovirus to promote the development of endogenous collateral vessels in ischaemic myocardium. The 


\section{Treatment of stable angina: key points}

- None of the three classes of antianginal drugs ( $\beta$-blockers, calcium channel blockers, nitrates) have been shown to reduce the rate of coronary events or mortality

- All patients should receive aspirin (75-325 mg daily)

- No role for clopidogrel treatment has been proven, except in aspirin allergy or post- $\mathrm{PCl}$

- Low density lipoprotein lowering (statin) treatment is recommended (target low density lipoprotein $<70 \mathrm{mg} / \mathrm{dl}$, $<1.81 \mathrm{mmol} / \mathrm{l})$

- ACE inhibitors are recommended for patients with diabetes, renal failure, hypertension, previous MI, left ventricular dysfunction, and uncontrolled risk factors

- CABG or percutaneous coronary revascularisation are feasible procedures in patients with inadequate or no response to antianginal drugs or in patients at high risk*

- Of all the new antianginal drugs, only nicorandil has been associated with improved outcome

- There is no definitive evidence to support $\mathrm{PCl}$ in all patients with stable angina except for symptomatic relief

*Left main or three-vessel coronary disease or two-vessel disease with significant lesions in the proximal left anterior descending artery, or multivessel disease in the presence of left ventricular dysfunction

delivery strategy includes transcatheter delivery via an intracoronary route, direct intraoperative intramyocardial injection, and catheter-based transendocardial injection, all of which may be incorporated with a magnetic guidance catheter-based navigational system that can distinguish between healthy and infarcted myocardium. All trials so far of FGF or VEGF with a placebo-controlled arm have produced negative results in terms of symptomatic relief or improving myocardial perfusion.

Autologous stem cell transplantation from bone marrow or peripheral blood has recently emerged as a promising therapeutic approach for ischaemic cardiomyopathy syndromes. Clinical studies indicated improvements in myocardial perfusion and function, although most investigated the use of this technique in the acute phase after MI. Small studies of intramyocardial, transepicardial or intracoronary injection of unselected mononuclear bone marrow cells in patients with coronary artery disease not amenable to conventional revascularisation techniques yielded improvements in anginal symptoms, exercise capacity, regional tissue perfusion and left ventricular systolic function. However, none included a randomised control group. The idea of improving myocardial perfusion by bone marrow cell injection is intriguing, and prospective large, randomised clinical trials are warranted.

\section{CONCLUSION}

Symptoms of chronic stable angina can usually be managed with optimum doses of one of the available antianginal drugs ( $\beta$ blockers, long-acting nitrates, or calcium channel blockers), alone or in combination. To slow the progression of atherosclerosis and reduce the incidence of MI and death, lifestyle modifications (smoking cessation, exercise, diet) together with pharmacologic treatment with aspirin, statins or ACE inhibitors are necessary. Several new drugs with a different mechanism of action (ranolazine, trimetazidine, nicorandil, ivabradine) provide new treatment options, though their precise indications, long-term impact and target population require further study. Patients who remain symptomatic despite medical treatment and patients with high-risk anatomy should be considered for revascularisation. Revascularisation should be viewed as complementary to aggressive medical treatment, rather than as an opposing strategy. Selected patients who do not respond to medical treatment and are not candidates for revascularisation may be considered for treatment with neurostimulation and EECP. The use of laser revascularisation has decreased because of its invasiveness and concerns that the promising results may be due to a placebo effect. Angiogenic gene therapy and myocardial cell therapy via multiple routes are being investigated to enhance local myocardial perfusion and function.

\section{INTERACTIVE MULTIPLE CHOICE QUESTIONS}

This Education in Heart article has an accompanying series of six EBAC accredited multiple choice questions (MCQs).

To access the questions, click on BMJ Learning: Take this module on BMJ Learning from the content box at the top right and bottom left of the online article. For more information please go to: http://heart.bmj.com/misc/education.dtl

Please note: The MCQs are hosted on BMJ Learning - the best available learning website for medical professionals from the BMJ Group.

If prompted, subscribers must sign into Heart with their journal's username and password. All users must also complete a one-time registration on BMJ Learning and subsequently log in (with a BMJ Learning username and password) on every visit.

\section{(...................}

\section{Authors' affiliations}

Itsik Ben-Dor, Alexander Battler, Department of Cardiology, Rabin Medical Center, Beilinson Campus, Petach Tikva, and Sackler Faculty of Medicine, Tel Aviv University, Tel Aviv, Israel

In compliance with EBAC/EACCME guidelines, all authors participating in Education in Heart have disclosed potential conflicts of interest that might cause a bias in the article

\section{REFERENCES}

1 Gibbons RJ, Abrams J, Chatterjee K, et al. ACC/AHA 2002 guideline update for the management of patients with chronic stable angina-summary article: a report of the American College of Cardiology/American Heart Association Task Force on practice guidelines (Committee on the Management of Patients With Chronic Stable Angina). J Am Coll Cardiol 2003;41:159-68.

- Clinical guidelines and recommendation for management of patients with stable angina.

2 Fihn SD, Williams SV, Daley J, et al. Guidelines for the management of patients with chronic stable angina: treatment. Ann Intern Med 2001;135:616-32.

3 Fox K, Garcia MA, Ardissino D, et al. Guidelines on the management of stable angina pectoris: executive summary: The Task Force on the Management of Stable Angina Pectoris of the European Society of Cardiology. Eur Heart $J$ 2006;27:1341-81.

- Recently published guidelines of the European Society of Cardiology on the management of patients with stable angina pectoris.

4 Heidenreich PA, McDonald KM, Hastie T, et al. Meta-analysis of trials comparing beta-blockers, calcium antagonists, and nitrates for stable angina. JAMA 1999;281:1927-36.

- Meta-analysis of 90 trials showing equivalent effectiveness of $\beta$-blocker, calcium antagonist and nitrates in the treatment of stable angina.

5 Poole-Wilson PA, Lubsen J, Kirwan BA, et al. Effect of long-acting nifedipine on mortality and cardiovascular morbidity in patients with stable angina requiring treatment (ACTION trial): randomised controlled trial. Lancet 2004;364:849-57.

6 Chaitman BR. Pharmacological approaches to the symptomatic treatment of chronic stable angina: a historical perspective and future directions. Can J Cardiol 2005;21:1031-4.

7 Siddiqui MA, Keam SJ. Ranolazine: a review of its use in chronic stable angina pectoris. Drugs 2006;66:693-710. 
8 Ciapponi A, Pizarro R, Harrison J. Trimetazidine for stable angina. Cochrane Database Syst Rev 2005;19:CD003614.

9 IONA Study Group. Effect of nicorandil on coronary events in patients with stable angina: the impact of nicorandil in angina (IONA) randomised trial. Lancet 2002;359:1269-75

10 Borer JS. Therapeutic effects of $I(f)$ blockade: evidence and perspective. Pharmacol Res 2006;53:440-5.

11 Abrams J. Clinical practice. Chronic stable angina. N Engl J Med 2005;352:2524-33.

874 Excellent recent clinical practice case for the treatment of stable angina.

12 Bhatt DL, Fox KA, Hacke W, et al. Clopidogrel and aspirin versus aspirin alone for the prevention of atherothrombotic events. N Engl J Med 2006;354:1706-17.

13 Opie LH, Commerford PJ, Gersh BJ. Controversies in stable coronary artery disease. Lancet 2006;367:69-78.

- This review stresses the controversies of three major aspects of the management of stable angina: risk factor assessment, drug treatment, and medical or surgical intervention.

14 Deckers JW, Goedhart DM, Boersma E, et al. Treatment benefit by perindopril in patients with stable coronary artery disease at different levels of risk. Eur Heart J 2006;27:796-801
15 Bucher HC, Hengstler P, Schindler C, et al. Percutaneous transluminal coronary angioplasty versus medical treatment for non-acute coronary heart disease: meta-analysis of randomised controlled trials. BMJ 2000;321:73-7.

16 Katritsis DG, loannidis JP. Percutaneous coronary intervention versus conservative therapy in nonacute coronary artery disease: a meta-analysis. Circulation 2005;111:2906-12.

- A useful meta-analysis comparing $\mathrm{PCl}$ versus conservative therapy in nonacute coronary artery disease.

17 Yang EH, Barsness GW, Gersh BJ, et al. Current and future treatment strategies for refractory angina. Mayo Clin Proc 2004;79:1284-92.

- An excellent review of the treatment strategies for refractory angina.

18 Kim MC, Kini A, Sharma SK. Refractory angina pectoris: mechanism and therapeutic options. J Am Coll Cardiol 2002;39:923-34.

Review discussing the mechanisms and therapeutic options for patients with stable angina.

19 DeJongste MJ, Tio RA, Foreman RD. Chronic therapeutically refractory angina pectoris. Heart 2004:90:225-30.

20 Leon MB, Kornowski R, Downey WE, et al. A blinded, randomized, placebocontrolled trial of percutaneous laser myocardial revascularization to improve angina symptoms in patients with severe coronary disease. J Am Coll Cardiol 2005;46:1812-9.

\section{MULTIPLE CHOICE QUESTIONS}

\section{Education in Heart Interactive (heart.bmj.com/misc/education.dtl)}

Education in Heart (EiH) articles each have an accompanying series of six multiple choice questions. These are hosted on BMJ Learning - the best available learning website for medical professionals from the BMJ Group. Each article is submitted to EBAC (European Board for Accreditation in Cardiology; ebac-cme.org) for 1 hour of external CPD credit.

Free access for subscribers: For full details of the resources available to subscribers please see: heart.bmj.com/misc/education.dtl\#access

How to access the questions: Click on BMJ Learning: Take this module on BMJ Learning from the online article content box, table of contents or EiH collection

(heart.bmi.com/cgi/collection/heart_education).

If prompted, subscribers must sign into Heart with their journal's username and password.

Please note: All users must also complete a one-time registration on BMJ Learning. Users will then subsequently log in (with a BMJ Learning username and password) on every visit in order to log activity and provide appropriate access.

Activating your subscription to Heart: If you have not yet activated your online subscription to Heart, please visit journals.bmj.com/cgi/activate/basic and enter your six digit (all numeric) customer number (found above your address label with your print copy). If you have any queries, please contact subscriptions@bmigroup.com

Case based learning: You may also be interested in the cardiology interactive case histories published in association with Heart, for more information please see: heart.bmi.com/misc/education.dtl\#ichs 